\title{
HE4 is a novel tissue marker for therapy response and progestin resistance in medium- and low-risk endometrial hyperplasia
}

Anne Ørbo, Marit Arnes, Lena Myreng Lyså, Christer Borgfeldt and Bjørn Straume

Correction to: British Journal of Cancer (2016) 115, 725-730. doi:10.1038/bjc.2016.247

Upon publication of the above paper in the British Journal of Cancer, the authors identified an error in the spelling of one of their names. The authors would like to apologise for this mistake. Christer Borgfeldt appears correctly in the author list above. 